\title{
EXPLORING AN INTEGRATED APPROACH TO WEB-BASED COURSE ASSESSMENT
}

\author{
Niu Jian (niujian@crtvu.edu.cn) \\ Xiao Junhong \\ Wang Zhongfeng \\ He Lanxiang \\ China Central Radio and Television University
}

\begin{abstract}
Web-based course assessment is a new thing at China's Open University - China Radio and Television Universities (China RTVUs). This article reports an innovative pilot study in this research area. The experimental course for integrated web-based assessment in this study is Advanced English Writing, which is a compulsory course in the B.A. English programme at China Central Radio and Television University (CCRTVU). The study started in March 2005 and it is still in progress at the moment. This article first describes the webbased assessment design of the course and the implementation procedures. Then it moves on to report some initial feedback from the student participants on the pilot study. The article ends with a tentative plan for further actions based on the current study.
\end{abstract}

Key words: CCRTVU, China RTVU, web-based assessment, web-based course

Assessment plays a central role in student learning. This is particularly true for distance learning. In a distance learning context, assessment can be used to motivate or pace learners to study, provide feedback on their performance and progress, increase learner-tutor interactions and ultimately help maintain academic standards and quality (Morgan and O'Reilly, 1999; Niu, 2003; Rowntree, 1987; Thorpe, 1998). In recent years, as the Internet access is increasingly available, web-based assessment has become a hot research area. A simple Google search for "web-based assessment", or "online assessment" or "Internet-based assessment" will result in hundreds of research reports in this area.

Web-based assessment is a new thing at China's Open University - China Radio and Television Universities (China RTVUs). In January 2005, China Central Radio and Television University (CCRTVU), which is the academic headquarters of China RTVUs, hosted a workshop in Beijing, discussing launching a pilot project in web-based course assessment. The purpose of the pilot project is to explore the feasibility of using the Internet as an efficient and cost-effective means of assessment. The goal is to make use of the advantages of the Internet technology to integrate assessment with learning and teaching so that online assessment can support distance learning and teaching. To achieve the goal, six courses were selected for the pilot project. The project started two months later in March 2005 and it is still in progress at the moment. 
This paper is intended to report web-based assessment of one of the six pilot courses - Advanced English Writing, a compulsory course in the B.A. English programme at CCRTVU. The paper will first describe the web-based assessment design of the course and the implementation procedures, and then move on to report some initial feedback from the student participants on the pilot study. The paper ends with a tentative plan for further actions based on the current study.

\section{WEB-BASED ASSESSMENT DESIGN AND IMPLEMENTATION}

\section{Setting up of a project team}

Advanced English Writing is a compulsory course in the B.A. English programme at CCRTVU. The course is run for one semester with 18 weeks. Its purpose is to improve students' writing proficiency. To carry out the pilot study, a course project team was set up. The first writer of this paper is course coordinator of Advanced English Writing at CCRTVU. He acts as head of the project team. The other three writers of this paper are course tutors at three local RTVUs. They are from Shantou Radio and Television University, Shannxi Radio and Television University and Beijing Radio and Television University respectively. They are the project team members. The three local tutors are included in the project team because they have been tutoring the course of Advanced English Writing for years and they are familiar with the course content and they understand student needs very well.

The project team designed a detailed course assessment plan before the pilot study started. Then the plan was implemented at the three local RTVUs where the three local team members are working. The three local team members work both as tutors and markers throughout the process of the pilot study.

\section{Principles in assessment design}

In the course of making the web-based assessment plan for the pilot study, the project team followed three principles. First, web-based assessment should combine continuous assessment and terminal or end-of-course assessment together. They should be designed as a whole. While taking into full account the different objectives and functions of the two types of assessment, we should integrate them into a mutually supportive framework so as to give full play to their respective strengths.

Second, both continuous assessment and terminal assessment are web-based. The former is conducted on CCRTVU's web-based Continuous Assessment Platform while the latter is administered on CCRTVU's web-based Terminal Assessment Platform. The web address of the platforms is http://www.etas.com.cn. The project team strongly maintains that web-based assessment does not mean that we simply move paper-based test items to the Internet or to a computer. Rather, we should make full use of the advantages of the Internet technology to achieve what is difficult to accomplish in a traditional paper-and-pen-based test. For example, web-based assessment activities can be designed in such ways so as to remind students regularly what tasks have to be completed by what time, to keep records of students' learning process and stimulate their reflection on learning, to allow flexibility in time and space for students to deliver their work, to provide students with timely feedback, to enhance student-tutor and student-student interactions, to strengthen students' collaboration and cultivate their team spirit, and to promote web-resource-based learning and develop students' information literacy (Niu, 2002; 2004). 
Third, web-based assessment should fit in with and help achieve the course aims. Advanced English Writing aims to improve students' writing skills. The project team believes in the old proverb of "Practice makes perfect". So every effort should be made to motivate students to write. Only when students are willing to practice writing and do not feel at a loss when faced with a writing assignment can we get them out of the familiar scenario at conventional writing tutorials where students usually feel they have nothing to write even when they are forced to.

\section{New approach}

The web-based course assessment for Advanced English Writing is made up of two components: continuous assessment and terminal assessment. The total score of the course is 100 marks. Continuous assessment covers $70 \%$ of the total score and terminal assessment covers the remaining $30 \%$. To prevent students from favoring one component over the other, it is stipulated that a student will fail the course unless he or she can get at least 42 out of 70 points from the continuous assessment and 18 out of 30 points from the terminal assessment at the same time. If he or she fails in either assessment, he or she will not pass the course.

Continuous assessment aims to facilitate learning and teaching (Niu, 2003; 2004). It is composed of four parts with a total of 24 tasks. All these tasks are conducted on CCRTVU's web-based Continuous Assessment Platform.

\section{- Part 1: Unit-based Self-Study Report}

Advanced English Writing consists of eight units and students are required to complete a self-study report for each unit. The purpose of this part is to motivate, guide and schedule students' pre-tutorial self-study. Students are asked to self-evaluate their learning performance in each unit and feed their learning difficulties or problems back to the tutor before the unit tutorial is given so that the tutor could prepare the tutorial in accordance with the feedback and thus improve the tutorial efficacy. Students can get 1 point for each report based on the criterion of timely submission. This part takes $8 \%$ of the total course score.

\section{- Part 2: Online Self-Assessment}

There are altogether four online self-assessment tasks, each covering two units of the course. Students are required to complete an online self-assessment task after they have learnt every two units. This part aims to allow students to self-check their mastery of the course content. Each task has 20 objective questions and takes 2.5 points. The four online self-assessment tasks make up 10 points in all, covering $10 \%$ of the total course score. In the answer keys to each test question, references to specific page numbers of the coursebook are provided so as to facilitate students' understanding of the relevant knowledge areas.

\section{- Part 3: Synchronous and Asynchronous Group Conferencing}

This part takes the form of online conferences, both synchronous and asynchronous. They are held in the BBS Forum of CCRTVU's Continuous Assessment Platform. The purpose of this part is to stimulate students' desire and interest in interacting with each other in written English and thus sharpen their writing skills. There is an online conference for each unit of the course and each conference lasts for two weeks. The topic for each conference is related to the content of each unit with specific instructions provided for students. In the synchronous conferencing section, students are 
required to have a group discussion on a given topic for at least an hour at the time chosen by the group members, and the contributions of each member should not be less than 150 words. After students have had their synchronous group discussion, they are expected to go on with the conference asynchronously at the remaining duration, posting more personal ideas or commenting on the group mates' messages. In the asynchronous section, each student should make at least eight contributions with a minimum of 250 words. The eight online conferences take 24 points with each assigned 3 points. This part takes $24 \%$ of the total course score.

\section{- Part 4: Offline Guided Compositions}

This part aims to develop and improve students' integrated writing skills by applying what they have learnt from the course. By reading, correcting and marking the compositions, tutors can have a comprehensive understanding of how well students have grasped relevant writing techniques. There are altogether four offline guided compositions. The compositions are expected to be built on the online conferences. If online conferences can be regarded as an opportunity of brainstorming, then students need to sort out their ideas and arguments and write them up in their offline guided compositions. Each composition should be no less than 300 words and accounts for 7 points, hence a total of 28 points for the four compositions. This part takes $28 \%$ of the total course score.

Terminal assessment, or the end-of-course assessment, aims to assess students' achievements at the end of a course of study. For the course of Advanced English Writing, terminal assessment aims to measure students' English writing proficiency. It takes the form of timed guided writing and it is administered on CCRTVU's web-based Terminal Assessment Platform. Students are offered five writing topics, which match the five major genres taught in the course. They are asked to choose one of the options and write a composition of a minimal length of 200 words within one hour. This part takes 30 points, covering $30 \%$ of the total course score.

To conclude, the project team has adopted an integrated approach to the web-based assessment of Advanced English Writing. In this new approach, assessment and learning and teaching are integrated. Assessment is meant to serve and support learning and teaching. Continuous assessment and terminal assessment are integrated. Online tasks and offline tasks are integrated. The goal is to make the best use of different assessment tasks to motivate students to learn and to write so that they can improve their English writing gradually.

\section{Assessment implementation}

In March 2005, at the beginning of the spring semester, the pilot web-based assessment of Advanced English Writing was launched at Shantou Radio and Television University, Shannxi Radio and Television University and Beijing Radio and Television University. A total of 74 students have taken part in the study on a voluntary basis. With the support of relevant universities, the project is now proceeding smoothly and will come to an end in mid-July.

\section{PRELIMINARY FINDINGS}

Up to the writing of this paper, the student participants have completed three fourths of the continuous assessment tasks. The terminal assessment will be administered in mid-July. However, through informal conversations with the student subjects and through observations of the changes they have made in their attitudes towards learning and in their coursework, the project team has 
collected some preliminary feedback from the students on the pilot study. The analysis shows that the students' overall reaction to the pilot project is positive.

First, the students are more enthusiastic about learning than before. It is widely acknowledged that this web-based course assessment is more suitable for adult learners because it can meet the demand for flexibility of study in time and space and for getting timely guidance from the tutors, which is essential for students' autonomous learning. A considerable number of students cannot afford the time for all face-to-face tutorials because of their career and family commitments. They used to worry about assignment deadlines or continuous assessment and have very few opportunities to practise using English out of school or exchange learning experiences with their classmates to learn from each other. All these worries are now gone with CCRTVU's Continuous Assessment Platform in operation. Now, they can make the best use of every minute available to study, whether early in the morning, in the mid-day or late in the evening, and wherever they are, either at home, in the work unit, at a hotel when they are away on a business tour, or even in an Internet bar. So far as they can access the Internet, they can do their coursework, get in touch with their peers, and ask their tutors for help.

Second, of all the assessment tasks in the continuous assessment, the online group conferencing is most welcome. The students reported that online group conferencing is the most effective way to improve their learning and writing. This is because each conference is an exchange of ideas in English between students themselves or between students and tutors in a context of genuine communication and therefore students can apply what they have learnt from the course to actual use. The conferences have obviously kept stirring up their interest in learning and writing. Furthermore, they can self-check their online performance, reflect on their own learning, and observe and learn from their peers even after the conferences are over.

Third, the pilot course offers a wider range of assessment activities, each of which has its focus points but all of which are interlinked properly. As a result, the different assessment activities have contributed to the same goal of improving students' writing proficiency. Compared with the writing of their counterparts doing the same course in the conventional way, the student participants' compositions tend to be more meaningful, interesting and organized in a more logical manner.

Fourth, most of the students are more time conscious than before, because each assessment activity has a time limit. They have to learn to schedule and manage their time and this in turn develops their learning autonomy.

Last but not the least, the students have improved their information literacy. They now know how to use the Internet to study, to interact with their peers or tutors and to accomplish a learning task. They have experienced and felt the power of the Internet technology in facilitating their learning.

\section{LIMITATIONS AND PROBLEMS}

Integrated web-based course assessment is new at CCRTVU. In addition, Advanced English Writing is the first course to experiment with this new approach among the six pilot courses. It started one month earlier than the other courses. Therefore, there have naturally arisen some problems. The problems fall into two broad categories: technical and pedagogical. 
The technical problems are primarily concerned with the design of CCRTVU's Continuous Assessment Platform. The platform is too complicatedly layered and structured. It is not very userfriendly. Besides, it is hardly adaptable to the specific needs of individual courses.

The pedagogical problems relate to the users in the first place - both students and tutors - who need courage and time to get used to the new approach. As assessment is interwoven with learning and teaching in the pilot project, we found that some students took long time to adapt themselves to the new mode of learning and assessment. Thus, we can easily imagine that if the project is extended to more RTVUs in the future, the training of students and tutors will be an essential step. The training will have to cover such areas as use of new educational technology, adoption of proper teaching and learning methods, strong web-based communication skills, etc.

Secondly, some assessment activities might need to be revised or redesigned. For instance, one of the purposes of the Unit-based Self-study Report is to act as a window through which tutors can monitor students' learning process so as to make informed decisions on what to lay emphasis on at the tutorial sessions. However, our investigation reveals that some students' performance has not lived up to our expectations. They did not rate their self-study highly and yet they failed to spot and specify their problems and difficulties in the report. As a result, the tutor could not have a true picture of exactly how well the students previewed the course materials. After investigation, we found that the questions in the report need to be redesigned. Some students reported that the current questions are a bit too general and they need to be more specific to the activities in a unit of study.

\section{TENTATIVE PLAN FOR FURTHER ACTIONS}

The pilot web-based assessment of Advanced English Writing will come to an end in mid-July. The project team will conduct a comprehensive and in-depth survey to collect all the subjects' feedback on the new approach. Revisions and further measures will be taken based on the findings of the study. It is hoped that the project will be extended to more RTVUs and to more courses in the future, as the preliminary findings have already indicated that web-based assessment is not only a realistic possibility, but also a plausible choice. It reflects the open and distance learning features and caters for the needs of adult learners.

\section{REFERENCES}

Morgan, C. \& O'Reilly, M. (1999). Assessing open and distance learners. London: Kogan Page.

Niu, J. \& Xu, Y. M. (2002). Online learning and distance learners. In Murphy, D., Shin. N. \& Zhang, W. Y (eds.), Advancing online learning in Asia (pp.26-38). Hong Kong: Open University of Hong Kong Press.

Niu, J. (2003). Validating a Unit-Based Learning Progress Report as an alternative method of progress assessment for distance learners in higher education. Unpublished doctoral dissertation. Hong Kong: The Hong Kong Polytechnic University.

Niu, J., He, L. X., \& Liu, Y. Q. (2004). Computer conferencing as a means of web-based progress assessment, Modern Educational Technology, 14(4), 30-37.

Rowntree, D. (1987). Assessing students: How shall we know them? (Revised Edition). London: Kogan Page/New York: Nichols Publishing Company. 
AAOU Journal, Vol. 1, No. 1, September 2005, 38-44

Thorpe, M. (1998). Assessment and 'Third Generation' Distance Education, Distance Education, 19(2), 265-286. 